\title{
ENTRE O TRABALHO ESCRAVO E O TRABALHO ASSALARIADO: A FORMAÇÃO DO MERCADO DE TRABALHO BRASILEIRO A PARTIR DAS OBRAS DE FLORESTAN FERNANDES E CAIO PRADO JÚNIOR
}

Jamile UlissesPereira

Mestranda em Desenvolvimento Econômico Universidade Federal do Rio Grande do Sul (UFRGS)

\begin{abstract}
Resumo - Este artigo tem como objetivo realizar uma exposição dos pensamentos de dois autores sobre o desenvolvimento capitalista brasileiro, são eles: Caio Prado Júnior e Florestan Fernandes. O foco temporal é na transição do modo de produção escravista para o assalariado como forma generalizada da relação de trabalho. Através desse apanhado podemos ver as diversas expressões de mediação das contradições inerentes à relação capital-trabalho, que assume configurações específicas de acordo com o padrão de acumulação vigente. Assim, partimos do pressuposto de que as relações trabalhistas são estruturalmente condicionadas pela forma de desenvolvimento e, utilizando esses autores, discutimos as especificidades dessa transição.
\end{abstract}

Palavras-chave: Modo de produção, Padrões de acumulação, Relações de trabalho.

\section{ENTRE O TRABALHO ESCRAVO E O TRABALHO ASSALARIADO: A FORMAÇÃO DO MERCADO DE TRABALHO BRASILEIRO A PARTIR DAS OBRAS DE FLORESTAN FERNANDES E CAIO PRADO JÚNIOR}

\begin{abstract}
Thispaper aims to hold an exhibition of the thoughts of two authors on the capitalist development in Brazil, they are: Caio Prado Júnior and Florestan Fernandes. The temporal focus is in transition from the slave mode of production to the employee as a generalized form of the employment relationship. Through this we can see the various expressions caught of mediation of contradictions inherent to the relationship between capital and labour, which takes on specific settings according to the pattern of accumulation. Thus, we start from the assumption that labour relations are structurally conditioned by way of developing and using these authors, we discuss the specifics of this transition.
\end{abstract}

Keywords: Mode of production, Accumulation patterns, Work relationships.

\section{INTRODUÇÃO}

Todas as mercadorias possuem uma mesma propriedade: serem produtos do trabalho. $\mathrm{O}$ desenvolvimento capitalista é, portanto e também, o desenvolvimento dos modos e das relações trabalhistas. Assim, o artigo inicia com Jorge Ben "Dum lado cana-de-açúcar. Do outro lado o cafezal [...] Sendo colhidos por mãos negras", passa por Clementina de Jesus "Tava durumindo, candonga me chamou. Disse: levanta povo, cativeiro já acabou!" e termina com Belchior "Era feito aquela gente honesta, boa e comovida. Que caminha para a morte pensando em vencer na vida [...] Que tem no fim da tarde a sensação da missão cumprida”.

Do trabalho escravo ao trabalho assalariado, em suas diferentes formas, outros tantos poderiam estar nesta introdução e deixar claro não só como a poesia popular ensina de forma bem mais interessante do que se seguirá, mas também comprovar a importância do tema, que deixa suas marcas no cotidiano até o ponto de virar poesia. Essas canções mostram de alguma maneira que a reprodução do capital se readequa às mudanças produzidas no sistema mundial e na divisão \begin{tabular}{l} 
internacional do trabalho (e o inverso), reorganizando a produção sobre novos eixos de \\
\hline REVISTA ECONOMIA POĹ́tICA DO DESENVOLVIMENTO
\end{tabular} 
acumulação e/ou valores de uso. Isso permite historicizar o processo, compreendendo as condições que tornam possível determinado padrão e não outro, além dos momentos de transição.

A passagem do capital pelas distintas formas de seu ciclo vai deixando marcas na produção e na circulação. Tais pegadas se convertem em trilhas quando são vários os capitais que se lançam ao investimento em determinados ramos e setores-eixo e que, com diferentes ritmos, mas em tempos determinados, vão realizando o ciclo ou processo de metamorfose. Perseguir essas pegadas e as trilhas que vão sendo criadas nos dá pistas de análise a fim de desvendar como o capital se reproduz em determinados momentos históricos (OSORIO, 2012, p.42).

Se utilizarmos a periodização de Mello (2009) para o Brasil, teremos as seguintes fases: economia colonial, economia mercantil escravista cafeeira nacional, economia exportadora capitalista, industrialização restringida e industrialização acelerada. Num nível mais concreto, essas etapas são definidas pelo que chamamos de padrão de acumulação, dando a estrutura de acumulação em cada momento. Quem também define esse processo é Tavares (1975); segundo a autora, o padrão de acumulação é definido por uma articulação específica entre a diferenciação da estrutura produtiva e a distribuição social da renda. A compreensão desse processo requer a identificação das relações básicas entre a estrutura da produção e da repartição, inerentes ao próprio processo de acumulação, e o modo pelo qual as condições de reprodução do sistema repõem ou modificam essa articulação básica da estrutura produtiva.

Utilizamos essa formulação, pois ela nos permite uma abordagem mais articulada sobre a relação entre economia e política, assinalando como diferentes padrões interagem com políticas econômicas distintas e dentro do nosso foco, como modificam as relações trabalhistas, sendo essas, assim, estruturalmente condicionadas.

O cenário estudado apresenta narrativas diversas. Esforços que se debruçaram na análise de um Brasil pensado em múltiplas vias e que pela heterogeneidade de interpretações já demonstram o caráter de sua importância reflexiva. Para Ianni (2000), uma das singularidades da história do Brasil é que esse é um país que se pensa, contínua e periodicamente, no contexto de conjunturas críticas ou a partir de dilemas que se criam quando ocorrem rupturas históricas. Aqueles pensadores que se destacaram como "Intérpretes do Brasil" foram construtores de visões a respeito do nosso desenvolvimento enquanto sociedade, gerando compreensões justas com as nossas particularidades. Dentre os temas recorrentes nos seus estudos sobressaem-se, como não poderia deixar de ser, a organização social e técnica do trabalho e da produção, focalizadas nas mais diversas acepções: escravos e senhores, empregadores e empregados, camponeses e latifundiários, entre outras categorias.

Partindo da preliminar de que a análise da realidade social precisa deslindar a formação e 
dinâmica dos grupos sociais, que enlaçam os movimentos da sociedade, expomos o processo lento de transição da forma de trabalho escravista para a forma assalariada, considerando que a primeira imprimiu e ainda imprime diferenciais determinantes nas relações de trabalho brasileiras. Para isso, as contribuições de dois "Intérpretes do Brasil" serão analisadas, a saber: Caio Prado Júnior (1907-1990) e Florestan Fernandes(1920-1995).

Ambos os autores debruçaram-se sobre o tema como uma questão fundamental para a compreensão de nossos problemas. Ao aproximarem-se do pensamento e do método marxista, embora com diferentes graus de ortodoxia, este entendimento não se fazia imperativo apenas pelo seu aspecto teórico, mas também pelo seu potencial transformador, pela capacidade que uma análise correta teria de propor soluções possíveis e adequadas. Como inspirado pela segunda tese sobre Feuerbach, Fernandes (1980) nos diz: "Trata-se de converter a teoria em força cultural e política (ou em força real), fazendo-se com que ela opere a partir de dentro e através de ações concretas de grupos, classes sociais ou conglomerados de classes".

Em relação ao método, esse autor mostrou-se bastante destoante por amalgamar pensamentos tidos como paralelos: o método funcionalista, ou objetivo, sistematizado por Durkheim; o compreensivo, formulado por Weber; e o dialético, criado por Marx (IANNI,1996). Outra novidade que o distancia de Caio Prado Júnior é a dissociação da revolução econômica da política, com a última precedendo à primeira. Esse fato ajudaria a explicar como o Brasil realiza seu processo de Independência política mantendo estruturas tipicamente coloniais, tais como a escravidão.

Caio Prado Júnior e Florestan Fernandes ajudaram a elucidar os "sentidos" da formação econômica e social brasileira, dessa forma, considerações intermináveis podem e vem sendo feitas ao longo dos anos a respeito de suas obras. Aproximações e divergências: esse é também o nosso objetivo. Retomaremos essas visões, pois mais uma vez se faz necessário repensar a realidade nacional. Assim, ao longo do trabalho iremos analisar e comparar suas ideias a respeito do destacado período, pois esses diagnósticosmarcaram fartamente não só as interpretações da época, mas também as seguintes, afinal de contas, como bem exprimiu Keynes, ideias antigas se insinuam pelos escaninhos do nosso entendimento.

\section{CAIO PRAdO JÚNIOR: A REVISÃo da REALIDAdE BRASILEIRA A PARTIR DE UMA DIALÉTICA REVOLUCIONÁRIA}

Uma boa maneira de iniciar o pensamento de Caio Prado talvez seja a partir da frase que diz que "a economia é o motor da história". Ao longo dos estudos é possível identificar inúmeras vezes essa sentença se encaixando e guiando seus diagnósticos. Sua investigação mostra como nas sociedades capitalistas a acumulação aparece como o essencial e as leituras tidas como não dialéticas são extremamente criticadas. 
É com essa base que o autor desaprova, inclusive, algumas percepções marxistas da época. Os exames criticados seriam apriorísticos, segundo o qual a humanidade em geral e cada país em particular, o Brasil incluído, passariam por uma evolução histórica etapista, onde os estágios sucessivos, iniciados invariavelmente no feudalismo, levariam ao capitalismo e posteriormente ao socialismo. Assim, presumiu-se que no Brasil o capitalismo foi precedido por uma fase feudal, e que os restos dessa fase ainda se encontravam presentes. Partiu-se dessa presunção para ir à procura, nas instituições vigentes, de alguma coincidência entre os fatos observados e o esquema pressuposto. Os traços encontrados foram enfocados e colocados em destaque, enquanto aquilo que de algum modo não se adequasse foi secundarizado ou deixado de lado. "Feudal" tornou-se sinônimo de qualquer forma particularmente extorsiva de exploração do trabalho, desconsiderando que tais formas, largamente difundidas nas relações de trabalho brasileiras, constituíam-se como remanescentes daescravidão.

De acordo com Curty et al. (2016), Caio Prado Júnior foi o primeiro autor a utilizar um método de análise que relacionava o estudo voltado à questão política com a pesquisa sobre a base material da sociedade brasileira, podendo ser considerado pioneiro na interpretação marxista do Brasil. Ele é também o primeiro a indicar uma ruptura com a corrente do "marxismo oficial" existente no Partido Comunista Brasileiro (PCB) ao se posicionar negando a forma feudal na controvérsia sobre o modo de produção vigente do Brasil colonial. Para ele, a colonização do continente americano em geral e a brasileira, em particular, estiveram definidas pelos impulsos do capitalismo comercial europeu, o sentindo da colonização, portanto, está inserido de forma dependente dentro do sistema capitalista mundial.

Tendo isso em vista, em Caio Prado Jr: História, de 1982, são apontadas as necessidades de uma caracterização precisa da verdadeira natureza das relações de trabalho brasileiras, situando não só que os pseudos restos feudais seriam restos escravistas ou servis, mas também colocando como indubitável que esse passado ainda pesasse na vida econômica e social de nossos dias, Prado Júnior (1982, p.191):

\footnotetext{
No Brasil, o que tivemos como organização econômica, desde o início da colonização, foi a escravidão servindo de base a uma economia mercantil. Com a abolição legal da escravidão (precedida de um processo de substituição progressiva do trabalho escravo pelo trabalho livre, desde a supressão do tráfico africano), era natural que as classes dominantes e senhoras dos meios e fatores de produção, inclusive e sobretudo a terra, procurassem se aproveitar da tradição escravista ainda muito próxima e viva, para o fim de intensificarem a exploração dotrabalhador.
}

A forma como se distribuiu a terra, onde o solo e seus recursos naturais constituíam-se como única riqueza resultou na seguinte forma de exploração: agricultura ou pecuária baseada na grande exploração rural e no trabalho escravo, do negro ou do índio, ou seja, a estrutura produtiva que se caracteriza por trabalho escravo (elemento mais essencial), monocultura e 
exportação latifundiária seria "a célula fundamental da economia agrária brasileira" (PRADO JÚNIOR, 2000, p.121). O senhor rural monopolizava a riqueza e com ela seus atributos: o prestígio e o domínio. A estrutura social da colônia no primeiro século e meio reduz-se em suma a duas classes: de um lado os proprietários rurais e de outro a massa da população dos trabalhadores do campo, escravos esemilivres.

Na obra Evolução Política do Brasil, publicada em 1933, podemos ver que até a segunda metade do século XVII coincidiam os interesses da Coroa com o dos proprietários de terra, entretanto, o cenário vai se alterando quando a economia nacional encontra por essa época a estreiteza do regime colonial como um obstáculo ao seu desenvolvimento. Revela-seentão a contradição fundamental que minava o regime: interesses nacionais e portugueses díspares. Com Portugal em decadência e o Brasil crescendo e complexificando sua economia (ao lado da economia agrícola, desenvolve-se o crédito e o comércio), a própria trajetória de acumulação trata de alinhar interesses opostos: de um lado os brasileiros, especialmente os proprietários rurais, a aristocracia fundiária nacional, que mais diretamente sofria o ônus da opressão colonial; de outro, os da metrópole, e a eles ligados, os dos mercadores portugueses, a burguesia comercial.

A partir dos diversos conflitos gerados por essa contradição no processo de acumulação, o autor enuncia que a emancipação política do Brasil resultou do desenvolvimento econômico do país, incompatível com o regime de colônia. Em outras palavras, é a superestrutura política do Brasil Colônia que, já não correspondendo ao estado das forças produtivas e à infraestrutura econômica do país, rompe-se, para dar lugar a outras formas mais adequadas, às novas condições econômicas e capazes de conter a sua evolução, como resumido por Haines e Fonseca (2011):

Como resultado desse processo, sucumbe a proeminência portuguesa, enquanto o Brasil se organiza em um Estado nacional "integrado na nova ordem internacional do capitalismo" e desencadeia um processo que "[...] comandará a evolução histórica e as transformações ocorridas até mesmo nos dias de hoje".

O Brasil, que com a abertura dos portos em 1808 e o desparecimento dos entraves coloniais entrava num período de notável surto econômico, ainda tinha como sua principal fonte de mão-de-obra o tráfico de escravos. Mesmo que as elites nativas tenham se apropriado do discurso liberal durante o processo de Independência, esse era feito de maneira instrumental, servindo para a "emancipação colonial", mas não para outros aspectos da vida social, econômica e política, tais como a escravidão. Havia, pelo contrário, o reconhecimento de uma absoluta necessidade dessa forma de trabalho para o desenvolvimento nacional.

A escravidão moderna só tem sentido histórico quando entendida como parte do processo de gestação da produção capitalista em escala mundial. Que o trabalhador seja assalariado nesse modo de produção é uma consequência do desenvolvimento desse sistema, da busca pelo lucro. A forma salarial é mais conveniente por fazer parecer que não há trabalho não pago, mas isso não implica que 
o sistema escravista brasileiro estivesse "fora de contexto" ou "atrasado", pelo contrário, esse sistema implicava o que Marx definiu como subsunção formal do processo de trabalho ao capital. Como processo de trabalho e de valorização, a essência formal é indiferente à situação jurídica do trabalhador, ante talcircunstância, o capital pode recorrer à coerção direta, como também pode fazer por outras razões que embarreiram a acumulação (HAINES E FONSECA, 2011).

A escravidão é responsável por inúmeros debates internos e externos no período. Enquanto uns traziam que o tráfico ainda correspondia ao estado das nossas forças produtivas, integrando-se perfeitamente na economia brasileira de então e fazendo uma defesa com base no direito à propriedade, a Inglaterra "aconselhava" a humanitária política de combater o comércio de africanos, com base também em seus interesses econômicos. De um lado, a preeminência comercial inglesa nas costas da África, ofuscada pelo prestígio dos traficantes negreiros, em geral portugueses. De outro, interesses nas colônias das Índias Ocidentais, que produziam, como nós, o açúcar e sofriam com a concorrência brasileira, avantajada pelo emprego do braço escravo. Somente após abundantes e reincidentes problemas diplomáticos, o Bill Aberdeen foi promulgado. Com a abolição do tráfico de escravos encerra-se a fase de transição que se estende desde a transferência da corte portuguesa para o Brasil. Ela será o último toque das séries de reformas que se sucedem para modificar uma colônia inteiramente submetida ao exclusivismo mercantil da metrópole portuguesa em Estado soberano aberto à livre concorrência internacional.

A proibição do tráfico negreiro liberou subitamente capitais consideráveis que se fizeram sentir com intensidade no mercado brasileiro. Caio Prado mostra que esse fato teve um imenso alcance, mudando completamente a face das coisas na agricultura, no comércio e na indústria. Os capitais que eram empregados no tráfico afluíram e a vida comercial se intensificou, estas intensas atividades se manifestam em grandes empreendimentos materiais no país, caracterizando a “modernização”. Como elucidado por Prado Júnior (1969,p.94):

\begin{abstract}
A velha estrutura colonial, varridos os obstáculos que se antepunham ao seu progresso, entra numa fase de completa remodelação. Seria na verdade um critério estreito atribuir esta transformação unicamente à abolição do tráfico de escravos. Ela estava naturalmente indicada pelas condições objetivas da economia universal, de que o Brasil entrava, com a Independência, a participar. Ensaiando o isolamento colonial, era inevitável, que o país se pusesse de acordo com essas condições. Mas é incontestável que este fato, a abolição do tráfico, constitui a vassourada preliminar e indispensável de tal surto de progresso. Ele abriu o nosso primeiro período de franca prosperidade comercial, alargando-se com ele os acanhados horizontes do mediavalismo brasileiro de então. Desenvolvimento de uma parte "progressista" da burguesia nacional ávida de reformas e cujos interesses estreitamente se vinculavam à transformação econômica do país.
\end{abstract}

A luta desses grupos burgueses, progressistas e conservadores, permeia o cenário político da segunda metade do XIX. Alista-se no primeiro principalmente o comércio e a finança. No segundo, os proprietários rurais. O eixo principal em torno de que se gira essa luta é a questão do elemento servil. Constituía já então o braço escravo o maior obstáculo ao 
desenvolvimento do país, não somente sua reconhecida improdutividade impedia progresso da nossa economia, como também, e principalmente, degradando o trabalho em geral, afugentava os trabalhadores livres. Assim, o abolicionismo nasce das condições objetivas do país, da insuficência qualitativa e quantitativa do trabalho escravo, e por efeito disto, do acúmulo de interesses opostos à escravidão. Essa evolução foi feita, portanto, pela integração sucessiva do país numa forma produtiva superior ${ }^{1}$.

Embora o crescimento econômico desse período se apresentasse nas aparências com o mesmo estilo do crescimento colonial, fundado na produção e exportação de matérias primas e produtos agrícolas, seu conteúdo e forma haviam se alterado. Para Oliveira (1984), a abolição é o fim do império, o baronato brasileiro passava à condição de classe dominante e de posse do principal meio de produção, a terra, detinha a total virtualidade de mediar o emprego da mão de obra e, portanto, de autonomizar-se e relação ao Estado. A abolição seria resultado de uma contradição entre a estrutura de produção e as condições de realização do produto, cuja solução foi a transformação de trabalho em força detrabalho.

Na obra História Econômica do Brasil, escrita em 1942, Caio Prado Júnior mostra como esta incipiente forma de capitalismo deu seus primeiros passos. A incorporação das primeiras companhias e sociedades assinala o início do processo de concentração de capitais que servirá de motor para a expansão das forças produtivas. Esta acumulação provém, sobretudo, da agricultura. Além disto, a substituição dos escravos por trabalhadores livres mobiliza os capitais que antes se invertiam naquela propriedade humana. Assim, grandes disponibilidades de capital até então fixos, tornam-se circulantes e desembaraçados para outras aplicações além do pagamento do trabalhoagrícola.

É período também de aparelhamento da vida financeira do país. A multiplicação dos bancos, das empresas financeiras em geral, das companhias de seguros, dos negócios de bolsa, permitem captar e mobilizar em escala que se vai fazendo significativa, as fontes da acumulação capitalista, o que colabora para o relativo progresso industrial; das manufaturas têxteis em particular.

A indústria nascente encontrará na população livre, mas pobre, um grande e barato suprimento de mão de obra. Esse grupo, que não encontrava lugar no sistema que se reduzia ao binômio senhor-escravo resultava em contingentes relativamente grandes de indivíduos mais ou menos desocupados. Será esta a origem do proletariado industrial brasileiro, permitindo entrosar no

\footnotetext{
${ }^{1}$ É também o início da indústria manufatureira no país, acentuando o caráter negativo da escravidão de um ponto de vista da estrutura produtiva. Nela não se empregarão trabalhadores servis, a não ser para tarefas acessórias. A constituição de um mercado de força de trabalho livre não é premissa da acumulação de capital enquanto essa transcorre na esfera mercantil, mas sua penetração na esfera da produção requer a disponibilidade de mão de obra livre. De um ponto de vista estritamente contabilístico, o escravo corresponde a um capital fixo cujo ciclo tem a duração da vida de um indivíduo; assim sendo, forma um adiantamento no longo prazo; enquanto o assalariado fornece sobretrabalho sem esse adiantamento. Nestas condições, o capitalismo é incompatível com a escravidão; foi o que se deu com o advento da indústriamoderna.
} 
trabalho produtivo normal uma categoria importante da população que vivera até aí à margem dele.

Ainda assim, é na estrutura anterior, voltada para uns poucos gêneros agrícolas destinados à exportação que se concentra a vida econômica do país. Faltava um mercado interno, o que as condições sociais e econômicas da maior parte da população brasileira não podiam oferecer. Não era possível às manufaturas nacionais concorrerem com a importação estrangeira proveniente de indústrias desenvolvidas. A economia brasileira estava, assim, presa em um círculo vicioso: ela se fundava naquilo que constituía sua fraqueza, a grande lavoura produtora de gêneros de exportação, que de forma controversa era a base da riqueza, mas também, em última análise, a responsável pelas acanhadas perspectivas do país.

Os efeitos desta contradição logo serão sentidos, pois começam a se abater as primeiras crises. Se de um lado a transformação do regime de trabalho assegurou o progresso do sistema produtivo do país, de outro ela se revelará um dos mais fortes elementos de desintegração da estrutura básica daquele sistema: a grande propriedade agrária.

Em primeiro lugar, o trabalho livre introduz um novo elemento sob o regime anterior da escravidão: a instabilidade da mão de obra. Tal contingência, particularmente grave num país de baixa densidade demográfica, forçará a adoção de um sistema de relações no trabalho que obrigasse o empregado, embora juridicamente livre, a conservar-se no seu lugar. Outra questão referente ao controle está no fato de que essa nova relação de trabalho substitui à subordinação "passiva" do antigo escravo por uma luta permanente sobre direitos e reivindicações. Esta situação terá grande importância na evolução da legislação brasileira, onde a administração pública será forçada a adotar medidas de proteção ao trabalhador rural contra excessos de seus patrões e zelar pelo cumprimento dos contratos de trabalho.

A par dessa evolução social e formando-lhe a base de sustentação é a economia que também se transforma. A estrutura da produção foi se modificando a fim de fazer face às novas solicitações e estímulos, e é isso que, para o autor, é esquematicamente o essencial da história do desenvolvimento brasileiro.

\section{FLORESTAN FERNANDES: MUDAR PARA CONSERVAR OU AS DEFORMAÇÕES DE UMA REVOLUÇÃO "DENTRO DA ORDEM"}

Inicio esta seção a partir da perspectiva de Florestan Fernandes sobre as muitas razões empíricas, teóricas e práticas - do estudo da mudança social, uma vez que o artigo tem como proposta discutir o período de transição do escravismo ao assalariamento.

Na obra Mudanças Sociais no Brasil, de 1960, o autor dialoga sobre como as sociedades humanas sempre se encontram em permanente transformação, por mais "estáveis" 
ou "estáticas" que elas pareçam ser. Assim, o estado "normal" de qualquer sociedade é um estado concreto em que ela se revela em funcionamento e, portanto, sob alguma combinação de movimentos de conservação e de ruptura. $\mathrm{O}$ ritmo e os tipos de mudança irão variar, sendo determinados pelas condições objetivas. Assim, a análise da mudança social na sociedade de classes brasileira deve combinar certo grau de autonomia do desenvolvimento interno com um mínimo de projeção hegemônica para fora. A investigação deve dedicar-se ao estudo do regime de classes: 1) sob condições tipicamente neocoloniais e 2) sob condições tipicamente de dependência econômica, sociocultural e política.

A primeira situação teria existido no Brasil na época da emancipação nacional e da eclosão interna do capitalismo. A segunda aparece nas últimas quatro décadas do século XIX, mas é apenas com a "integração do mercado interno" e o industrialismo, que ela iria amadurecer. Sob a ode de que o conhecimento a respeito da formação do regime de classes exige o estudo da primeira situação, são nos desdobramentos que ocorrem na segunda que se pode descobrir uma explicação sociológica para o presente e para o futuro, ou seja, o que o regime de classes reserva à periferia do mundo. A partir dessas lentes se desdobra o diagnóstico de Florestan Fernandes em A Revolução Burguesa no Brasil, publicada a primeira vez em 1975, esta é a obra a qual daremos destaque e iniciamos seu estudo a seguir.

Para Caio Prado Júnior não haveria motivos para se falar em Revolução Burguesa no Brasil, uma vez que o país fruto da expansão do capitalismo comercial português e configurandose como um espaço geográfico para a acumulação que já nasce sob o signo do capitalismo manteve ao longo do seu processo histórico o sentido da colonização. Mesmo com a Independência ou a transformação do escravo em trabalhador livre, não podemos, segundo ele, falar sobre uma cisão de burguesias. A inexistência de uma burguesia retrógrada ligada ao capital internacional e outra, nacional, faria perder o fundamental da ideia de Revolução Burguesa.

Em contraposição, Fernandes argumenta que o senhor de engenho, a despeito de seus privilégios, ainda ocupava uma posição marginal e subordinada à metrópole, não preenchendo, de fato, os papéis socioeconômicos os quais poderiam ser associados ao "burguês". Assim, houve a necessidade de uma Revolução Burguesa e esta não teria sido um mero episódio histórico, mas um fenômeno estrutural que se inscrevia na longa gestação da ordem social competitiva. A Independência teria sido um evento paradigmático ao iniciar o processo de autonomia política e, com ela, a formação da sociedade nacional. A implementação de um Estado nacional independente constituía a única via pela qual se poderia romper o bloqueio à autonomia e à plena autorrealização dos estamentos senhoriais e fornecia-lhes, ao mesmo tempo, o caminho mais fácil para a extensão do patrimonialismo do nível doméstico, da unidade de produção e da localidade para o da "comunidade estamental" propriamente dita, oferecendo 
aos estamentos senhoriais a oportunidade histórica para o privilegiamento político do prestígio social exclusivo que eles desfrutavam material e moralmente, na estratificação da sociedade.

As alterações políticas resultantes condicionaram a reorganização da sociedade e da economia, inserindo as estruturas econômicas coloniais dentro de uma nova ordem legal, estimulando a organização e o crescimento de um mercado interno e configurando uma situação de mercado que se tornaria, bem depressa e segundo um ritmo de aceleração crescente, o principal polarizador do desenvolvimento econômico nacional. A economia brasileira ganhara certos substratos materiais ou morais e os dinamismos econômicos básicos para assimilar os modelos de organização econômica predominantes nas economias centrais.

A convergência de interesses burgueses internos e externos fazia da dominação burguesa uma fonte de estabilidade econômica e política. Só ela dispunha de poder em toda sua extensão, podendo oferecer aos setores intermediários a maior segurança possível na passagem do mundo pré-capitalista para o mundo capitalista, prevenindo a desordem da economia, a dissolução da propriedade ou o desgoverno da sociedade. Ao fechar o espaço político, a burguesia garante-se como único caminho para a continuidade e expansão do capitalismo dependente.

Logo, o processo de Independência, ao não ser constituído através das manifestações das grandes massas populares, não negou a ordem social imperante. Nessa perspectiva, a Independência pressupunha, lado a lado, um elemento revolucionário e outro conservador. $\mathrm{O}$ elemento revolucionário era o componente dinâmico e aparecia nos propósitos de despojar a ordem social, herdada da sociedade colonial, requisito para que ela adquirisse a elasticidade e a autonomia exigidas por uma sociedade nacional. O elemento conservador evidenciava-se nos propósitos de preservar e fortalecer uma ordem social que não possuía condições materiais e morais suficientes para engendrar o padrão de autonomianecessário.

A grande lavoura e a mineração, que continuavam como base produtiva, impunham a perpetuação das estruturas do mundo colonial, tais como a escravidão, a extrema concentração da renda e o monopólio do poder por reduzidas elites, com a marginalização permanente da enorme massa de homens livres. Essas características fizeram com que Fernandes visse a autonomia do país como um fenômeno medularmente político, uma vez que não teria havido transformação prévia, concomitante ou subsequente das relações de produção, mas sim a vinculação desses padrões de organização, estrutural e dinamicamente, às tendências de integração, diferenciação e crescimento da economiainterna.

Há, no período, concentração do poder político no nível dos privilégios senhoriais, onde a "sociedade civil" e "estamentos sociais dominantes" passaram a ser quase sinônimos. Essa situação fomentou um desequilíbrio persistente entre o comportamento político das elites e a 
ordem legal, instituída sob o modelo ideal de um Estado nacional com influências do liberalismo. Em consequência, esta perdia sua eficácia onde ou quando colidisse com os interesses gerais dos estamentos senhoriais. Dessa forma, o Estado preenchia duas funções: 1) manter as estruturas sociais de privilégio e 2) expandir ou fomentar o aparecimento de condições econômicas, sociais e culturais que deveriam formar o substrato de uma sociedade nacional.

O aparecimento de um Estado nacional, a burocratização do domínio das elites e a expansão econômica colocavam em novas bases as funções econômicas e sociais dos estamentos intermediários e superiores. São necessárias inúmeras alterações nos comércios de exportação, importação e a criação de novas instituições. A internalização do fluxo de renda contribuiu para a liberação e a dinamização de móveis puramente capitalistas do comportamento econômico e deram novas bases a uma economia de mercado pelo aparecimento e aumento de grupos de consumidores, expandindo o comércio.

O campo de ação da política econômica e do Estado, de forma geral, é extenso e cobre praticamente todos os terrenos que o capital percorre em seu ciclo e em sua reprodução. Assim, auxiliando o capital em seu ciclo, o Estado primeiramente foi fiel aos princípios do liberalismo ao orientar-se na proteção da iniciativa privada; mas posteriormente assumiu vários encargos. Desde aqueles que pretendiam garantir a continuidade da mão de obra escrava até o estabelecimento de meios de comunicação e transporte, criação dos serviços públicos, fixação de colônias etc., visando à gestação de estruturas econômicas requeridas por uma sociedade nacional.

A Revolução Burguesa se dá sobre os fracos alicerces lançados pela autonomização política do País, superando apenas parcialmente as limitações da situação de mercado engendrada pelo "neocolonialismo econômico". O período pós-colonial consistiu na consolidação de uma forma de dominação exclusivamente econômica que substituísse as formas de dominação política superadas pela ruptura do regime colonial. Surgem, nesse momento, esforços localizados de internalização das fases de comércio e de certo "nacionalismo econômico", que visava superar a condição marginal nas relações econômicas com o mercado externo. Basicamente, o que ocorre é a substituição de uma situação de marginalidade política com o exterior por uma situação de marginalidade econômica.

Entretanto, é da contradição entre dependência econômica e autonomia política que surgem os elementos que vão possibilitar o ponto de partida para transformações técnicas, capitais e modelos de ação econômica. Carmo (2009) esquematiza o surgimento da noção de mercado em Florestan Fernandes com base em três "enlaces distintos", são eles: a) o enlace da economia interna com o mercado mundial e particularmente com o mercado externo hegemônico, no caso a Inglaterra; b) o enlace do mercado capitalista moderno à cidade e; c) o enlace do mercado capitalista moderno com o sistema de produção escravista. A autora vai defender a existência de 
uma interdependência entre a produção escravista e o desenvolvimento urbano, pois ao tentar consolidar o mercado capitalista moderno em um contexto de produção escravista, há a exclusão de uma significativa parcela de consumidores e um nível de concentração de riqueza a ponto que a aristocracia agrária começar a investir no mercado interno.

Da aparente contradição entre o setor agrário exportador e dos novos setores comerciais internos é que surge a possibilidade de transformação da economia. $\mathrm{O}$ excedente gerado pela atividade exportadora passa a ser aplicado produtivamente na cidade, dando vida a novas atividades e a algum grau de redistribuição, como elucida Fernandes (1981,p.101):

\begin{abstract}
Mantendo-se estáveis certas tendências estruturais de circulação e redistribuição de renda, podiam aumentar a diversidade e o ritmo de suas atividades econômicas, elevando suas probabilidades de acumulação de capital acima dos limites de participação da renda da aristocracia agrária. [...] Explica-se, assim, como uma condição nuclearmente heteronômica pudesse gerar a sua própria negação e a sua superação.
\end{abstract}

As pressões do desenvolvimento urbano sobre a diferenciação do consumo são relevantes para gerar algum grau de dinamismo interno, o que possibilitaria a consolidação posterior de elementos autônomos capazes de gerar crescimento econômico. Desse processo de dinamização interno desenvolve-se um setor de produção agrícola, artesanal ou manufatureira destinada ao consumo interno e a utilização dos excedentes como fator de autonomização da vida econômica. Ainda assim, esses desenvolvimentos, nesse momento, não ameaçam a situação heteronômica da economia nacional, cujo dinamismo segue atrelado, sobretudo, ao setor exportador.

Dessa forma, os modelos das economias centrais não podem ser transplantados, expondo a especificidade da Revolução Burguesa em uma economia colonial, periférica ou dependente. Fernandes define como um capitalismo de tipo especial, montado sobre uma estrutura de mercado que possuía duas dimensões - uma estruturalmente heteronômica; outra com tendências dinâmicas autonômicas ainda em vias de integração estrutural. A superação dessa estrutura só poderia se dar a partir de núcleos ligados ao desenvolvimento e à autonomização da vida econômica interna, ou seja, fora da especialização produtiva de base primária exportadora.

As estruturas sociais, econômicas e políticas coloniais, não só moldaram a sociedade nacional subsequente como também determinaram as proporções e o alcance dos dinamismos econômicos absorvidos no mercado mundial. Elas se revelaram bastante plásticas no que se poderia chamar de reorganização do mercado colonial. No entanto, mostraram-se rígidas na absorção dos dinamismos econômicos que eram centrais para a expansão interna do capitalismo, tais como a generalização da mão de obra livre. Nessa esfera, os condicionamentos externos dependiam do quão rápido as estruturas coloniais podiam ser demolidas.

A emergência e a formação da ordem social competitiva ocorreram, assim, paulatinamente, à medida que a desintegração da ordem social escravocrata e senhorial forneceu pontos de partida 
consistentes para a reorganização das relações de produção, trabalho e de mercado sobre bases genuinamente capitalistas. Logo, para o Fernandes, o abolicionismo começava e terminava com a problemática histórica do branco rico e poderoso, combatia-se não a escravidão em si mesma, porém o que ela representava como anomalia numa sociedade que extinguira o estatuto colonial e pretendia organizar-se como nação. Precisava-se destruir a escravidão para acabar com os entraves da ordem escravocrata e senhorial à expansão interna do capitalismo.

De acordo com Motta (2013), a abolição da escravidão marca a transição para o regime de classes e o alvorecer da ordem social competitiva, no qual a competição e o mercado já apareciam como fatores de classificação social. Entretanto, esses elementos vem extremamente carregados dos elementos tradicionais e a abolição não garantiu que a massa de ex-escravos participasse de forma integrada do novo mercado de trabalho. É a partir da constatação dessa integração limitada nas novas estruturas sociais que Florestan percebe a desigualdade e como o regime de segregação social se desenvolve e persiste como frutos dasrelações sociais do passado colonial. A competição surge como um circuito social estreito que só aplica aos "iguais".

Comprometido com o estudo da questão racial, Florestan Fernandes apresenta sua visão a respeito desse processo em diferentes obras. Ilustraremos seu pensamento sobre essa questão com passagens do livro Integração do negro na sociedade de classes:

\begin{abstract}
A desagregação do regime escravocrata e senhorial se operou, no Brasil, sem que se cercasse a destituição dos antigos agentes de trabalho escravo de assistência e garantias que os protegessem na transição para o sistema de trabalho livre. Os senhores foram eximidos da responsabilidade pela manutenção e segurança dos libertos, sem que o Estado, a Igreja ou qualquer outra instituição assumisse encargos especiais, que tivessem por objeto prepará-los para o novo regime de organização da vida e do trabalho. [...] Essas facetas da situação [...] imprimiram à Abolição o caráter de uma espoliação extrema e cruel (FERNANDES, 2008, p.29).
\end{abstract}

A desintegração da sociedade estamental e de castas não os favoreceu socialmente [os negros], pois eles se convertem, rapidamente, em elementos residuais do sistema social (FERNANDES, 2008, p.62).

[...] lutaram [os negros] com furor, mas como pólo heteronômico e alienado contra essa "situação de castas"; e emergiram em plena era de reconstrução social, diante de uma "situação de classes" substancialmente diversa da anterior em sua ordenação e potencialidades, com loucas esperanças, mas ainda na mesma condição de pólo heteronômico e alienado. Para onde quer que se voltassem, mesmo nas oportunidades mais modestas, tinha pela frente o "colono", o "imigrante operário", o "artista europeu" ou elementos da plebe nacional que antes não disputavam, por indignas, as suas ocupações. Como arrostar essa imprevista e pesadíssima concorrência direta com o "homem branco" sem sequer saber, coletivamente, o que ela significava e como aproveitá-la? (FERNANDES, 2008, p. 64).

Cabe a ressalva de que o a substituição do trabalho escravo pelo trabalho do imigrante formalmente livre já vinha ocorrendo antes da Abolição. Segundo Motta (2012), a combinação entre essas duas formas de relação de trabalho era conflituosa, pois a escravidão rebaixava a remuneração do trabalho "livre", mas a questão central do processo abolicionista, do ponto de vista da estrutura 
social, consistia na mudança para os setores dominantes, os senhores que se convertiam em "homem de negócios". Do ponto de vista dos setores subalternos, a lenta transição para a universalização do trabalho formalmente livre, a chegada maciça de imigrantes e o racismo serão elementos essenciais para pensarmos os limites dessas alterações. Só a partir dessas observações podemos teorizar sobre quem foram os agentes do trabalho assalariado no país e como desde o início da ordem social competitiva as relações de trabalho foram modificadas pelo alto.

A perpetuação das relações tradicionais é uma característica do capitalismo dependente e, segundo Florestan, essas relações, no Brasil, resistem em quase tudo que é fundamental para esse tipo de desenvolvimento, tais como a posse da terra, a espoliação sistemática e a marginalização dos pobres e, principalmente, nos padrões de relações étnicas e raciais (FERNANDES, 2007). O regime de classes que se desenvolve a partir daí, em conexão com o capitalismo dependente, apresentaria dois pólos: um interno, representado por classes dominantes que se beneficiam da extrema concentração da riqueza, do prestígio social e do poder; e outro externo, representado pelos setores das economias centrais. Na medida em que a burguesia nacional luta pelo desenvolvimento capitalista em termos de uma política de associação dependente, ela se articula ativamente aos variados interessesexternos.

Dessa forma, as classes dominantes internas usam o Estado para fazer face e, se possível, neutralizar: 1) as pressões internas dos setores marginalizados e das classes agora já assalariadas; 2) as pressões externas vinculadas aos interesses das nações capitalistas hegemônicas e à atuação da "comunidade internacional de negócios"; 3) as pressões de um Estado intervencionista, fortemente burocratizado e tecnocratizado. Em vista disso, o Estado deve ser visto como uma condensação material da relação de forças entre as classes sociais existentes, isto é, uma relação social. Como aponta Poulantzas (1978), a burocracia de Estado é multifacetada, possuindo interesses e projetos políticos contraditórios, sem uma vontade política unívoca. Há a fração burguesa hegemônica dentro do bloco no poder, mas esta muda ao longo do tempo, o que pode influenciar a própria política do Estado, dependendo das condições histórico-estruturais e da dinâmica da luta política. Se o Estado não é integralmente produzido pelos grupos dominantes, não o é também por eles monopolizado. Mas sem dúvidas, como aponta o próprio Florestan Fernandes, ele pode se tornar arma de opressão e de repressão, que servindo a interesses particularistas, objetiva a preservação e a ampliação de privilégios econômicos, socioculturais e políticos.

Nesse contexto de apropriação dual do excedente econômico (setores internos e externos), a base material para a formação e a expansão da ordem social competitiva torna-se muito fraca e vacilante de maneira que a mudança social é comprimida, convertendo-se, extensa e profundamente, em um processo de "modernização dependente". 
Em suma, o que extraímos dessa explanação é que o desenvolvimento capitalista progride sem um padrão de caráter universal e invariável. No caso brasileiro, nas três fases distinguidas pelo autor como de desenvolvimento interno do capitalismo, a saber: a) fase de eclosão de um mercado capitalista (abertura dos portos até a crise da produção escravista); b) fase de formação e expansão do capitalismo competitivo (consolidação da economia urbano- comercial até a década de 1950); c) fase de irrupção do capitalismo monopolista (apresenta como marco temporal o Golpe de 1964), nenhuma delas impôs uma ruptura com a associaçãodependente, a desagregação completa do antigo regime e a superação de estados relativos ao subdesenvolvimento. Isso demonstra que, para Florestan, o desenvolvimento sempre foi capitaneado e apropriado pelas elites. Com um domínio tão claro e extenso desse grupo, também foram eles que definiram o inimigo comum da nação: no passado, o escravo; no presente, o assalariado do campo ou da cidade. Com essa definição, ela protegia tanto as fontes de acumulação pré-capitalistas, que deram lastro ao crescimento interno do capitalismo competitivo, quanto o modelo de acumulação propriamente desenvolvido, nascido com a mercantilização do trabalho.

\section{CONSIDERAÇÕESFINAIS}

O panorama estudado a partir das obras desses dois pensadores sociais se faz necessário para entender as contradições, sobretudo as distributivas, entre as classes sociais. Para isso, tentamos destacar as elaborações teóricas que identificavam as relações socioeconômicas básicas que foram inerentes ao próprio processo de acumulação do período.

Diferentes estudiosos apontam que nos estudos de economia política e história econômica, uma das tarefas mais difíceis para o pesquisador marxista, categoria teórica a qual os dois se aproximam, é captar o movimento do capital em sua processualidade no contexto de situações histórico-concretas, pois isto exige transitar em diferentes níveis de abstração. Sem dúvidas, os autores estudados elaboram seus diagnósticos dessa forma. Ao condensar as inúmeras variáveis presentes nesse processo de transição, assim como o conjunto de regularidades dentro desse tempo histórico e espaço definidos, compreendemos a nossa formação social de forma totalizante, casando os aspectos internos com a relação do país no sistemamundial.

Séries de continuímos podem ser vistos em nossas considerações analíticas a respeito de ambos os autores. Permanências relacionadas ao sentido da colonização, para Caio Prado Júnior ou inerentes ao capitalismo dependente, para Florestan Fernandes. A prevalência do padrão primário exportador atravessando a reprodução do capital no país 
desde o século XIX é um exemplo. É fundamental mencionar, nesse contexto, a Lei de Terras do ano de 1850, que beneficiava grandes proprietários no bojo da apropriação de terrenos e favorecia a criação de uma massa de expropriados, aviltados da oportunidade da posse fundiária, mesmo em um contexto de abundância de terras.

Tendo em vista essas observações, é importante salientar que para ambos a superação da dominação econômica externa só seria possível na medida em que se extinguisse apredominância econômica da grande lavoura exportadora. Essa estrutura produtiva, extremamente concentrada e que sobreviveu durante mais de 350 anos baseada na exploração de mão de obra escrava contribuiu, indubitavelmente, para diversos aspectos elementares na formatação autocrática das relações de trabalho brasileiras.

Ainda que Florestan Fernandes veja no capitalismo brasileiro um nascimento progressivamente lento e Caio Prado não, ao assinalar a existência desse modo de produção desde nossa configuração enquanto país, ambos chegam a conclusões parecidas em relação ao desencanto com a ação das elites e consequentemente com a ideia de alianças em associação a elas em busca do desenvolvimento econômico nacional. Por vias diferentes, nas quais o primeiro combina a análise das etapas de acumulação do capital com elementos socioculturais, enquanto o segundo mantém-se mais próximo da ortodoxia marxista, ambos confluem sobre as características autoritárias dos grupos dominantes e dos processosde mudanças sociaisocorridos.

Fica claro, assim, que o desenvolvimento econômico, sobretudo em uma economia como a nossa, se dá em um estado permanente de atritos. Logo, faz-se fundamental, para qualquer um preocupado com o substantivo de se estudar economia, ou seja, as pessoas, que o estudo das relações entre a estrutura da produção e da repartição da renda seja realizado. As relações de trabalho são um norteador chave para qualquer pesquisa nesse sentido.

Apesar das considerações a respeito das continuidades, concluo destacando o aspecto revolucionário dessa transição, presente em ambos os autores. Revolução entendida aqui de forma ampla e como um conceito que também confluiu em ambos, ou seja, revolução como um processo histórico assinalado por reformas e modificações político-econômicas que, concentradas em um período de tempo determinado, resultam em transformações estruturais.

O estudo da mudança social pode até ter a alçada, para alguns mais otimistas, talvez, de realizar previsões. Por enquanto, a única previsão que arrisco fazer é a da 
certeza da mudança e a noção de que esta estará em disputa. Logo, a nossa forma de trabalho e as relações que estabelecemos com os produtos do nosso trabalho também. Ao tomarmos esses autores como exemplo, relações de trabalho apenas "formalmente livres" não serão suficientes, a busca feita era por emancipação com uma crítica severa aos conceitosde liberdade que se associavam a ideia de propriedade. Em tempos de novas configurações das relações de trabalho, colocadas como flexíveis, quem poderá se opor à validade dessas análises?

\section{REFERÊNCIAS BIBLIOGRÁFICAS}

CARMO, R.A.E. As etapas do desenvolvimento capitalista no Brasil. In: V Colóquio Internacional Marx e Engels, 2009. Anais do V Colóquio Internacional Marx e Engels. Campinas, 2009, v.5, p.1-10.

CURY, C.; MALTA, M.M.; VIEIRA, W.; LEON, J; PINHEIRO, F.L. A controvérsia dos

modos de produção brasileiros: a contribuição do pensamento marxista. In: XVII Seminário sobre a Economia Mineira, 2016, Diamantina - MG. Anais do XVII Seminário sobre a Economia Mineira. Belo Horizonte: UFMG/CEDEPLAR, 2016. v.3.p.52-69.

FERNANDES, F. A Integração do Negro na Sociedade de Classes. São Paulo, O Globo. 2008.

A natureza sociológica da sociologia. São Paulo, Ática,1980.

O negro no mundo dos brancos. $2^{a}$ edição: São Paulo: Global,2007.

. A Revolução Burguesa no Brasil. São Paulo, Zahar,1981.

. Mudanças sociais no Brasil. São Paulo, Global Editora,2013.

HAINES, A, FONSECA P. 2011. A escravidão colonial brasileira na visão de Caio Prado Junior e Jacob Gorender: uma apreciação crítica. Ensaios FEE. 32:161-196.

IANNI, Octávio. A Sociologia de Florestan Fernandes. Estudos Avançados, São Paulo, v. 10, n.26, p.2533, jun.1996.

IANNI, Octávio. Tendências do Pensamento Brasileiro. Tempo Social, São Paulo, v. 12, n. 2, p.55- 74, nov. 2000.

MELLO, João Manuel C. O capitalismo tardio. São Paulo: Ed. Unesp, 2009.

MOTTA, D. C. As particularidades do regime de classes no Brasil segundo Florestan Fernandes. In: V Simpósio Internacional Lutas Sociais na América Latina, 2013, Londrina - PR. Anais do V Simpósio Internacional Lutas Sociais na América Latina, 2013.

MOTTA, D. C. Desvendando mitos: as relações entre "raça" e classe na obra de Florestan Fernandes. Dissertação de Mestrado, IFCH- Unicamp. Campinas- SP, 2012.

OLIVEIRA, F. A emergência do modo de produção de mercadorias: uma interpretação teórica da economia da República Velha no Brasil (1889-1930). In: A economia da dependência imperfeita. Rio de Janeiro, Edições Graal,1984. 
OSORIO, Jaime. América Latina: o novo padrão exportador de especialização produtiva - estudo de cinco economias da região. In: Padrão de reprodução do capital: contribuições da teoria marxista da dependência. Carla Ferreira, Jaime Osorio, Mathias Luce (Org.). São Paulo: Boitempo, 2012.

PRADO JUNIOR, Caio. Formação do Brasil contemporâneo. São Paulo: Publifolha, 2000.

Caio Prado Jr: História. São Paulo, Ática,1982.

Evolução Política do Brasil. 6. ed. São Paulo, Brasiliense, 1969.

História Econômica do Brasil. 12. ed. São Paulo, Brasiliense, 1970.

A Revolução Brasileira. 7. ed. São Paulo, Brasiliense, 1987. POULANTZAS, N. State, Power, Socialism. London : New Left,1978.

TAVARES, M.C. Distribuição de Renda, acumulação e padrões de industrialização: um ensaio preliminar. In TOLIPAN, R.M.L. e TINELLI, A. C. A. Controvérsia sobre Distribuição de Renda e Desenvolvimento. Rio de Janeiro, Zahar,1975. 